\title{
“CIÊNCIA E DOMINAÇÃO”: A IMAGEM DO INDÍGENA AMAZÔNICO PELO OLHAR LUSO-BRASILEIRO, À LUZ DAS CIÊNCIAS ILUSTRADAS NA VIAGEM DE ALEXANDRE RODRIGUES FERREIRA
}

Natally Nobre Guimarães Orientação: Martha Daisson Hameister e Magnus Roberto de Mello Pereira

PALAVRAS-CHAVE: iluminismo português; schemata; Alexandre Rodrigues Ferreira.

O indígena foi recorrente objeto de descrição pelo olhar europeu. Tendo em vista que as representações pictóricas e textuais não são apriorísticas, mas construídas socialmente, pode-se considerar que as representações sobre o indígena passaram por esse processo de elaboração desde que a Europa travou contato com as populações americanas, representadas ora como habitantes do Paraíso Terrestre, ora como criaturas diabólicas. No século XVIII, o projeto iluminista de conhecimento sistemático do mundo natural deu seqüência a esse processo de representação, estimulando a produção de muitas memórias, relatos e correspondências a respeito das nações indígenas.

A presente pesquisa investigou as representações do indígena amazônico nas representações produzidas pela Expedição Filosófica de Alexandre Rodrigues Ferreira. A metodologia que foi empregada deriva da análise de schematas propostas por Gombrich. ${ }^{1}$ A análise de schematas foi desenvolvida por Ernst Gombrich para o estudo da presença de representações corpóreas da arte greco-romana na arte renascentista. O método de Gombrich já foi utilizado por ChicanganaBayona para analisar as influências da arte greco-romana nas gravuras com imagens de indígenas do período renascentista,

${ }^{1}$ GOMBRICH, Ernst. Arte e Ilusão: um estudo da psicologia da representação pictórica. São Paulo: Martins Fontes, 1995. 
conforme ilustração abaixo.
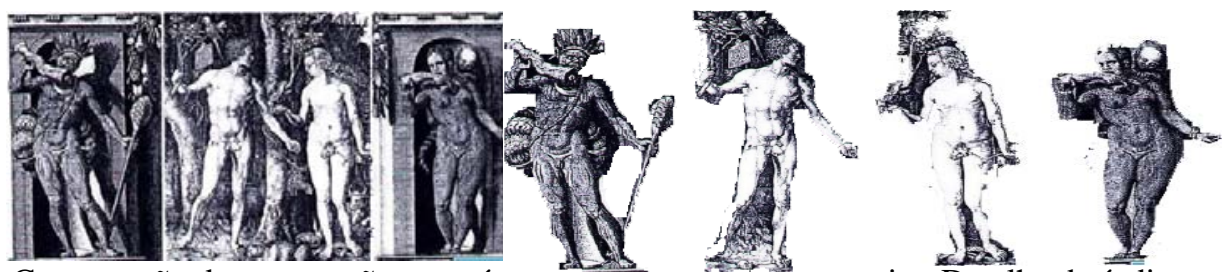

Comparação das proporções corpóreas: da esquerđa para a dıreita: Detalhe do índio Tupinambá do Frontispício. Theodoro de Bry. Americae Tertia Pars, gravura, 1592. Albrecht Dürer. Adão e Eva ou a Queda do Homem. Gravura sobre chapa de cobre 24,8 x 19,2cm, Museu Albertina, Viena, 1504. Detalhe da índia Tupinambá do Frontispício.

Como conclusão de seu trabalho, notou que os indivíduos são fisicamente semelhantes. São cenários diferentes com os mesmos modelos humanos. Adão e Eva compõem um cenário de serenidade e harmonia, numa composição na natureza do Novo Mundo e do Velho. O casal Tupinambá de Theodoro de Bry também traz em seu cenário alguns produtos característicos do Novo Mundo, como os cachos de frutas, mas demonstra agressividade nos gestos. O que define o mundo ao qual cada casal pertence são os adornos e adereços. ${ }^{2}$

Realizaram-se experimentações sobre as representações tanto pictóricas quanto textuais produzidas pela expedição de Alexandre Rodrigues Ferreira. Entende-se aqui que texto e gravura são partes integrantes de uma mesma schemata indígena, cada uma guardando as peculiaridades próprias do tipo de linguagem ao qual pertence, e em discordância com Ronald Raminelli, que afirma serem portadoras de conteúdos diferentes devendo ser sujeitas a análises em separado. ${ }^{3}$

2 CHICANGANA-BAYONA, Yobenjin Aucardo. Do Apolo de Belvedere ao guerreiro tupinambá: etnografia e convenções renascentistas. História, São Paulo, v. 25, n. 2, p. 15-47, 2006.

3 RAMINELLI, R. Do conhecimento físico e moral dos povos: iconografia e taxionomia na Viagem Filosófica de Alexandre Rodrigues Ferreira. História, Ciências, Saúde. Manguinhos, vol. VIII (suplemento), 969-92, 2001, p. 973. 
Estendeu-se o que em Gombrich, Chicangana e Moutinho ${ }^{4}$ é aplicado somente sobre as representações pictóricas, à parte textual do conjunto de relatos produzidos na Expedição de Alexandre Rodrigues Ferreira.

Estruturou-se a monografia em três capítulos que são ao mesmo tempo temáticos e cronológicos, contendo como ilustração os experimentos realizados no corpus documental que serviu de base para a pesquisa. O primeiro capítulo analisa as representações referentes aos primeiros contatos entre indígenas e europeus. Nelas, analisa-se o imaginário que se constrói a respeito do Novo Mundo e de seus habitantes desde os primeiros contatos, traçando um retrospecto de mitos e lendas da cosmologia européia. ${ }^{5} \mathrm{O}$ significado destas "imagens" do outro é condicionado pelo meio social em que são construídas, citando Hall: "as coisas não significam: construímos o seu significado socialmente, utilizando sistema de representação conceitos e signos". ${ }^{\circ}$

No capítulo seguinte verificam-se as mudanças na forma de observar e de representar o indígena entre os séculos XVI e XVIII. O Sistema Naturae, publicado em 1735 por Lineu, foi a obra decisiva para a sistematização e organização da natureza. Uma série de manuais para orientar o olhar e a descrição do mundo natural passou a ser publicada, tendo por base o seu sistema de classificação. Lineu torna a gravura um instrumento importante para as descrições, principalmente na Botânica. ${ }^{7}$

Esse projeto científico foi marcado pela atuação do Marquês

\footnotetext{
${ }^{4}$ MOUTINHO, Lucia A. A produção iconográfica de Ângelo Donatti no contexto ilustrado português. Curitiba, 2004. Monografia (Graduação em História) - Setor de Ciencias Humanas, Letras e Artes, Universidade Federal do Paraná.

5 MAGASICH-AIROLA, J.; BEER, Jean J. América Mágica. São Paulo: Paz e Terra, 2000.

6 HALL, Stuart. Identidades Culturais na Pós-modernidade. Rio de Janeiro: DP\&A, 1997. p. 24. apud OLIVEIRA, Teresinha Silva de. Do Canibalismo ao Planalto, das Pajelanças às Práticas ‘civilizadas': Representação de Índio em Revistas. Rio de Janeiro: ANPED n. 30, 2007, p. 2.

${ }^{7}$ MOUTINHO, op.cit., p. 39.
} 
de Pombal, Ministro de D. José I. ${ }^{8}$ Pombal foi o responsável pela reorganização de Lisboa após o grande terremoto de 1750, empreendendo diversas reformas, principalmente na educação, com a criação do complexo d'Ajuda e a reforma da Universidade de Coimbra. Para esta houve a contratação de especialistas em ciências naturais, como Domingos Vandelli e Julio Matiazzi, que irão instruir a intelectualidade lusa nestas ciências. Na década de 1780, Portugal passou a promover seus próprios manuais, como o Methodo de Recolher, Preparar, Remeter e Conservar os Productos Naturais, voltados a orientar o olhar sobre a natureza dos domínios do Império. Descrições sobre fauna, flora, mineração, agricultura e as populações nativas já vinham sendo enviadas de diversas partes do Império por governadores e capitães, entre outros.

No terceiro capítulo discutem-se as representações do indígena na Viagem Filosófica empreendida pelo naturalista Alexandre Rodrigues Ferreira, sob o prisma das schematas. Nascido na Bahia em 27 de abril de 1756, Ferreira bacharelou-se em História Natural na Universidade de Coimbra aos 22 anos. Em 1783 regressou ao Brasil em uma expedição que se prolongou até meados de $1792^{9}$, acompanhado de Agostinho Joaquim do Cabo (botânico), Joaquim José Codina e José Joaquim Freire (desenhistas). A expedição percorreu as capitanias do Rio Negro, Grão-Pará, Maranhão e Mato Grosso. ${ }^{10}$ As produções da expedição podem ser encontradas principalmente no Museu Bocage e no Arquivo Histórico Ultramarino, em Portugal, e no Instituto Histórico e Geográfico Brasileiro.

Analisaram-se aqui as memórias referentes às nações indígenas, a memória sobre os mamíferos, o Diário da Viagem ao Rio

\footnotetext{
${ }^{8}$ MAXWELL, Kenneth. Marquês de Pombal: paradoxo do Iluminismo. Rio de Janeiro: Paz e Terra, 1996. p. 17.

9 SIMON, Willian Joel. Scientific expeditions in the Portuguese overseas territories. Lisboa: Instituto de Investigação Tropical, 1983.

${ }^{10}$ PEREIRA, Magnus Roberto de Mello. Um Jovem Naturalista num ninho de Cobras: a trajetória de João da Silva Feijó em Cabo Verde em finais do século XVIII. História: Questões e Debates, Curitiba, n. 36, 2002, p. 31.
} 
Negro, e correspondências ainda não impressas localizadas no IHGB. Observou-se nesse conjunto a presença de quatro schematas.

A primeira schemata percebida é a influenciada pelas representações renascentistas. Os indígenas no Renascimento são compostos por uma transposição de valores e expectativas européias. O frontispício do Americae Tertia Pars de Theodore de Bry, juntamente com os relatos de Caminha e Vespúcio, são exemplos recorrentes desta transposição através de um dualismo entre o habitante do Paraíso e o bárbaro canibal.

Nas gravuras abaixo observa-se que o corpo do indígena não é representado de acordo com o padrão artístico de representação do homem europeu, que, como apontado por Gombrich, estava baseado nas representações corpóreas clássicas. Observa-se nas gravuras abaixo que a disposição dos membros segue o padrão da arte grecoromana, demonstrando que tradição e a técnica permanecem os mesmos. Como o indígena estava sendo entendido como uma subespécie humana, sua representação pictórica foi particularizada com a simplificação de suas formas corpóreas como músculos e feições.
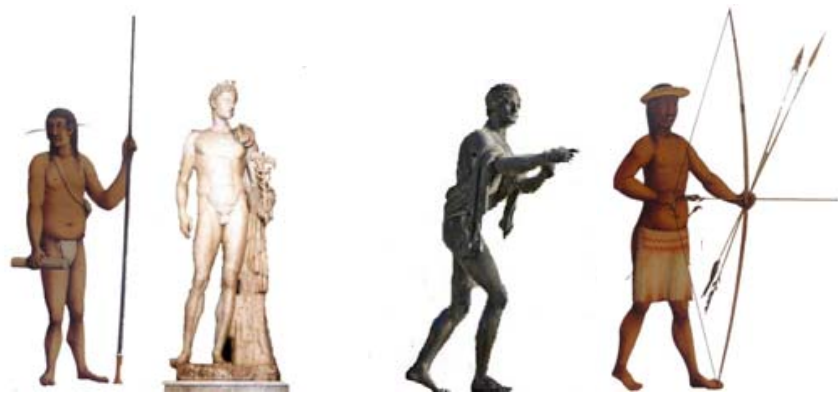

Gentio Miranha, estátua de Hermes, estátua de Apolo, do Santuário de Pompéia, e Gentio Mura.

O que se altera é forma como se quer o índio representado. As poses representadas nas estampas dos gentios Mura e Miranha são muito semelhantes às das estátuas de deuses. O que se está representando é a subespécie humana Tapuia. Sua inferioridade ao europeu observada na gravura é também descrita textualmente. O 
nativo Mura oscila entre inimigo dos portugueses e instrumento destes. De corsário canibal, na descrição da Memória, o gentio Mura é representado como bom cristão em correspondências. Assim como Caminha e Vespúcio ao descreverem a natureza, os povos e povoações encontrados, de mulheres luxuriosas e homens fortes a canibais ardilosos, Ferreira descreve este dualismo nas descrições dos indígenas Mura e Miranha.

Da ferocidade desta nação (...) e dos malefícios e insultos com que ela tem perseguido a agricultura, a população, o comércio, e a navegação (...) por sua natureza conserva cruel e irreconciliável inimizade com todas as mais nações (...) que professa por instituto a pirataria (...) são antropófagos”. ${ }^{11}$

Certifico que, no dia nove do mês de junho deste ano de mil setecentos e oitenta e cinco, nesta dita igreja, batizei solenemente e pus os santos óleos a vinte inocentes (...), todas da nação mura, e por se me ter pedido pelos pais (...) O vigário fr. José de Santa Teresa Neves. ${ }^{12}$

O terrível guerreiro canibal Mura da primeira citação dá lugar ao devotado cristão da segunda. A ferocidade e a boa fé da nação são elementos que se revezam nas representações, de acordo com o interesse colono no momento em que o documento está sendo redigido.

A segunda schemata é a do Americanus Paraensibus Tapuia. Ferreira os define como: Mamífero, Quadrupede, Divisão $1^{a}$ dos Terrestres, Homo Paraensibus Lusitanis, Spécies $1^{a}$ Sapiens, Variedade Americanus Paraensibus Tapuia, ${ }^{13}$ subdivididos em monstruosos por natureza e monstruosos por artifício. A semelhança física entre os indígenas representados mostra que derivam de um mesmo modelo. Observando as gravuras nota-se a mesma relação de disposição corporal que Chicangana havia percebido entre as estátuas

${ }^{11}$ FERREIRA, Alexandre Rodrigues. Viagem filosófica pelas capitanias do Pará, Rio Negro, Mato Grosso e Cuiabá. Memórias: antropologia. Rio de Janeiro: Conselho Federal de Cultura, 1974, pp. 85-86.

12 FERREIRA, Alexandre Rodrigues. Viagem ao Brasil. São Paulo. Kapa Editorial, v. 2, 2003, p. 123.

${ }^{13}$ FERREIRA, op.cit., p. 73. 
gregas e as gravuras de De Bry. Removeram-se aqui suas armas e coloração. Confirma-se que se trata do mesmo indígena apenas com vestuário e poses diferentes.
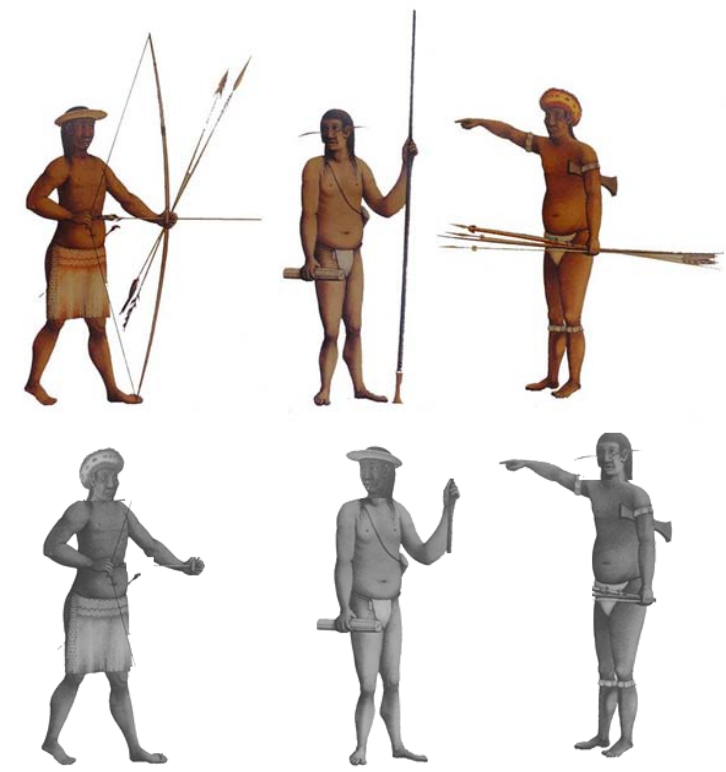

Comparação entre as representações corpóreas: Imagens dos índios Mura, Miranha e Curutu, retiradas da Viagem Filosófica de Alexandre Rodrigues Ferreira, Kapa

Editorial, 2002.

A diferenciação entre a representação do corpo do indígena e a do homem europeu é considerada por Ronald Raminelli como inaptidão dos desenhistas. ${ }^{14}$ Colocando lado a lado o busto do Mura e a estampa do Miranha, produzidos pelos desenhistas da expedição, percebe-se que não é esse o motivo. O Mura foi reproduzido com abundância de detalhes, jogo de luz e sombra, com boa volumetria e proporção. A diferença de técnica entre as duas gravuras está no objetivo. O Miranha, de corpo inteiro em seu "habitat", mantém a pose de uma estátua clássica, mesmo em detrimento do real,

${ }^{14}$ RAMINELLI, op.cit., p. 972. 
percebido pelo tamanho do braço esquerdo, que, se esticado, fica bem maior que o direito. $\mathrm{O}$ indígena foi representado como uma subespécie humana, com uma sub-representação corporal onde o modelo de posicionamento foi preservado e o delineamento dos músculos e feições foi relaxado.

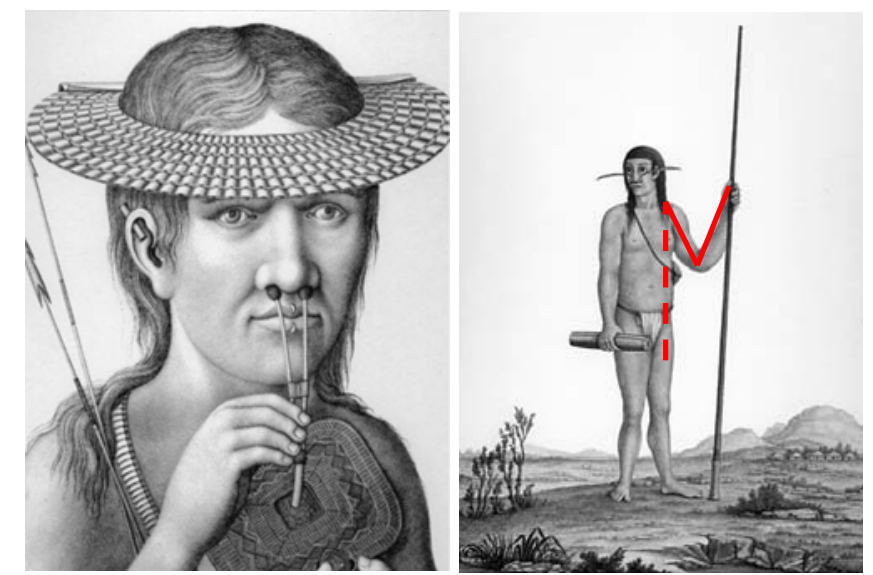

Na esquerda Gentio da Nação Mura, na direita Gentio Miranha.

A terceira schemata é aqui denominada científica. A representação do indígena pela Filosofia Natural como quadrúpede terrestre é baseada em uma tipologia inspirada em Aristóteles e Plínio, que consideram o aspecto maravilhoso da natureza, privilegiando as peculiaridades das nações. Haviam tipologias específicas aonde as nações indígenas eram enquadradas para serem representadas para o público europeu.

A história e origem dos povos, a ordem que observão no governo, os costumes e ceremonias pintura, e Escultura e o methodo finalm ${ }^{\text {te }}$ porque trabalhão com semelhantes Artes... Fará o curiozo Naturalista desenhos, e descriçoens exatas dos teares, officinas, instrumentos e machinas, de q' se usão... o genero de comércio que ha entre aquella Nação ...a Agricultura e Lavoura de cada Paiz; ...As materias de que estes povos se servem para os seus vestidos, methodo porq' os fazem... As doenças que se exprimentão, os remedios de que particularmente se servem os particulares do paiz com 
a utilidade que tiram do seu uso. ${ }^{15}$

O texto científico era a memória, sendo boa parte das produzidas durante a expedição acompanhada por gravuras em forma de estampas. Ferreira enuncia o nome de cada nação e descreve a localidade onde podem ser encontradas, as características exóticas, os costumes, religião, forma de matrimônio, a indústria que produzem, e as armas que utilizam, como se pede nas instruções. Montei a tabela abaixo para dar mais clareza à forma como estas instruções se vêem presentes no texto da memória.

\begin{tabular}{|c|c|c|c|c|c|c|c|c|}
\hline Nação & Local & $\begin{array}{c}\text { Caracter } \\
\text { ísticas }\end{array}$ & $\begin{array}{c}\text { Costu } \\
\text { mes }\end{array}$ & Religião & $\begin{array}{c}\text { Casam } \\
\text { ento }\end{array}$ & Armas & $\begin{array}{c}\text { Indúst } \\
\text { ria }\end{array}$ & Autoria \\
\hline 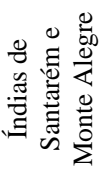 & 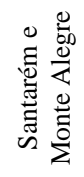 & 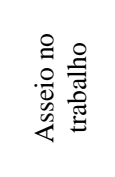 & 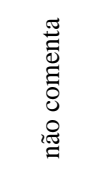 & 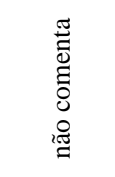 & 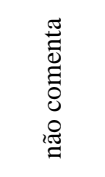 & $\begin{array}{l}\stackrel{0}{\Xi} \\
\stackrel{\Xi}{\Xi} \\
0 \\
0 \\
\stackrel{2}{\Xi}\end{array}$ & 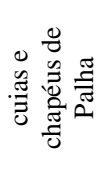 & 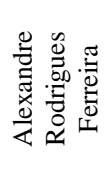 \\
\hline$\stackrel{\mathbb{Z}}{\stackrel{\Xi}{2}}$ & 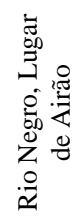 & 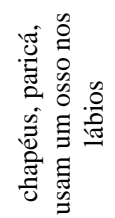 & 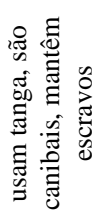 & 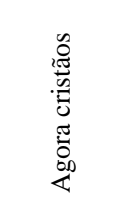 & 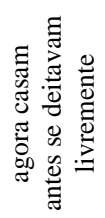 & 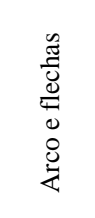 & 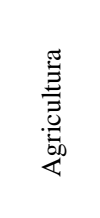 & 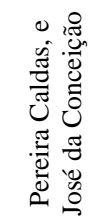 \\
\hline
\end{tabular}

As gravuras em forma de estampa davam visibilidade às descrições feitas em texto. O naturalista e seus desenhistas enfatizavam as peculiaridades de cada nação, como as testas alongadas dos Cambebas, as pinturas dos Yurupixunas e os espartilhos dos Mauhás. Estas características serviam de orientação primária na identificação das tribos. A gravura da memória geralmente continha uma legenda com informações básicas, como o nome e a localidade habitada pela nação. A imagem tanto realçava o

${ }^{15}$ VIDIGAL, Agostinho José Martins. Methodo de fazer observações e exames necessários para o augmento da Historia Natural, com os meios de Preparar, conservar, e dispor nos Museos os diversos productos da Natureza. Biblioteca Nacional de Lisboa. Cota MSS 8520. 
que estava descrito no texto, como poderia ser "lida" individualmente. A schemata de um indígena enquadrado no modelo básico de descrição é transmitida de forma textual e iconográfica, sem ser comprometida pelas especificidades das linguagens.
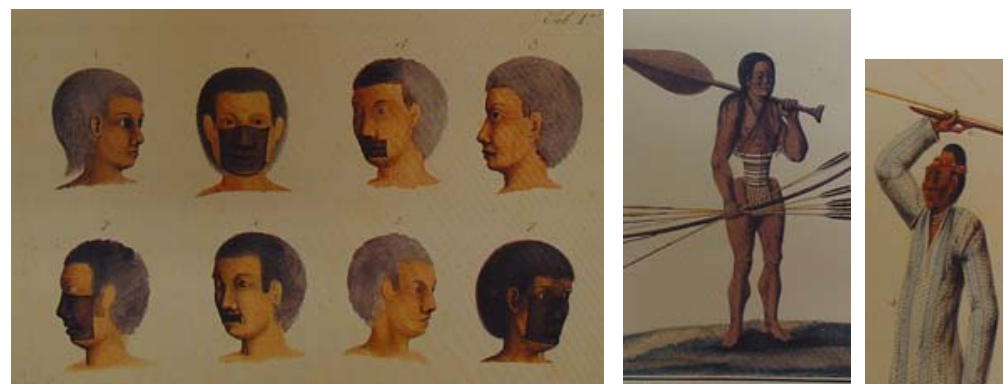

Da esquerda para a direita: imagens de índios Yurupixunas, Mauhá e Cambeba, retiradas da Viagem Filosófica de Alexandre Rodrigues Ferreira. São Paulo, Kapa Editorial, 2002, p. 59, 32 e 06.

Há ainda um quarto índio representado em correspondências e memórias pela expedição, o indígena civilizado. Ele vem representando sua função na sociedade junto aos colonos, e não mais como objeto exótico da natureza. ${ }^{16}$ As índias das vilas de Barcelos, Santarém e Vista Alegre aparecem nas memórias apenas como fabricantes de artesanato:

A título de empregarem as índias em algum trabalho lucrativo para elas e evitarem a ociosidade, distribuem por elas, e principalmente pelas mestras, diversas encomendas de pacarás, tabuleiros, chapéus, etc., não para as pagarem à razão dos 1.600 e 1.200 , que valem, e cujo valor hão de dobrar na Cidade, mas para lhes pagarem por dia à razão de 40 réis. Se a índia, que bem percebe a desigualdade do partido, se demora mais tempo do que o consignado pelo Diretor para concluir a obra, é notada de preguiçosa e

${ }^{16}$ CRUZ, A. L. R. Verdades por mim vistas e observadas, Oxalá foram fábulas sonhadas: cientistas brasileiros do Setecentos, uma leitura auto-etnográfica. Curitiba, 2004. Tese (Doutorado em História) - Setor de Ciencias Humanas, Letras e Artes, Universidade Federal do Paraná. 
castigada com palmatoadas. ${ }^{17}$

Os índios que trabalham na expedição aparecem nas correspondências e diluídos nas paisagens representadas.

Índios preparadores dos Productos 2 São os mêsmos, que subirão com a Expedição, e há 6 annos, que bem, e fielmente servem a Sua Magestade. Pelo que de si mesmos fazem recomendáveis à bondade de V. Exª., para nos ordenados, que vencêrem, os attender $\mathrm{V}$. Ex ${ }^{\mathrm{a}}$, , como for Razão e Justiça. $^{18}$

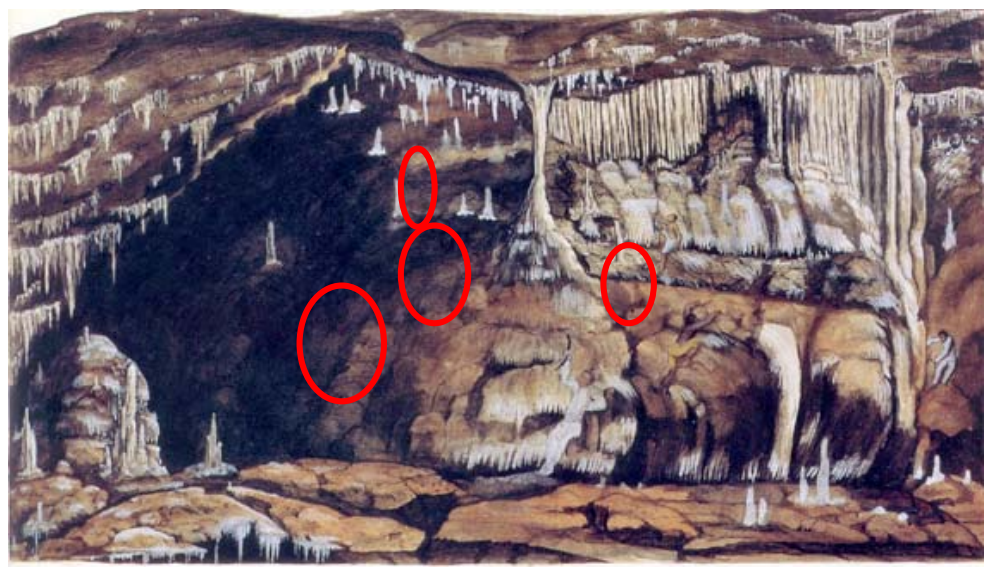

${ }^{17}$ FERREIRA, Alexandre Rodrigues. Viagem Filosófica pelas Capitanias do Grão Pará, Rio Negro e Cuiabá. Memórias - Antropologia. Departamento de Imprensa Nacional, 1974, p. 47-48.

${ }^{18}$ FERREIRA, A. R. Carta a João de Albuquerque de Melo Pereira e Cáceres em Vila Bela, 21 de Maio de 1790. IHGB Lata 195, Pasta 62, Doc, 04. 


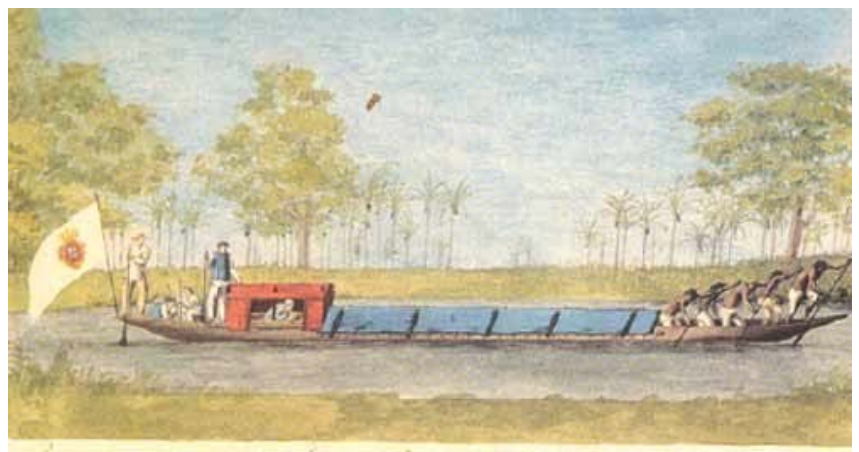

Da esquerda para a direita: Gruta do Inferno e Canoa pelo rio Cuyabá, Viagem Filosófica de Alexandre Rodrigues Ferreira. São Paulo, Kapa Editorial, 2002.

O indígena não está invisível, aparece nas gravuras imiscuído à paisagem; não é o objeto da gravura, mas está representando a sua função: os remeiros da canoa e os trabalhadores que servem como escala humana na gravura da Gruta do Inferno. As índias que fazem artesanato, os preparadores e os remeiros compõem a representação de um índio pelo prisma utilitarista. Ferreira é filho de um comerciante baiano, um "crioulo" branco dominante representante da elite. A schemata aqui construída é baseada nesta sua origem, e nas relações que mantém com a elite local, aqui representada por capitães e governadores. É a representação do indígena que aparece todo o tempo, “sem aparecer”. Aquele que está prestando serviço, que torna as coisas possíveis, mas é praticamente omitido do relato. Ele é construído a partir de sua utilidade para a sociedade colonial.

Através da metodologia gombrichiana foi possível a identificação de pelo menos quatro schematas; outras mais podem vir a ser identificadas através de mais pesquisas. Estas schematas são distintas entre si, mas não isoladas: elas se cruzam através dos relatos e imagens, cada uma com seu próprio significado. 